\title{
SYPHILIS AMONG STD CLINIC PATIENTS IN PRAGUE IN 2009
}

\author{
Ivana Kuklová1, Petr Velčevský', Martina Kojanová ${ }^{2}$ \\ 'Department of Dermatovenereology, 1st Faculty of Medicine, Charles University and General Teaching Hospital, Prague, Czech Republic \\ ${ }^{2}$ Department of Dermatovenereology, General Teaching Hospital, Prague, Czech Republic
}

\section{SUMMARY}

The aim of the study was to evaluate clinical, epidemiological and demographic data of patients with syphilis hospitalized at the Department of Dermatovenereology of the General Teaching Hospital in 2009 and to identify the groups at high risk of sexually transmitted diseases. The results were compared with the previous surveys carried out between 1999 and 2005 and also with the data of the National Registry of Venereal Diseases for 2008.

A total of 232 patients were hospitalized in 2009 (including 26 women admitted for compulsory retreatment in pregnancy). We noticed a $25 \%$ increase in the number of patients in comparison with the year 2008. Of the total number of patients, 206 were patients with newly diagnosed syphilis, of which $153(74.3 \%)$ were men and $53(25.7 \%)$ women. There was $22.3 \%$ of patients with primary and $31.6 \%$ with secondary syphilis. As in the previous years, heterosexual contact remained the most frequent route of syphilis transmission. However, the number of homosexual and bisexual men increased, amounting to $64.7 \%$ of all hospitalized men. Four men were HIV positive. The age distribution did not change; majority of the patients were aged between 30 and 40 . The proportion of foreigners also remained unchanged (19.9\%); they came mainly from the Slovak Republic (31.1\%) and Ukraine (26.7\%). The absolute number of reported syphilis cases has been increasing in the Czech Republic since 2006. From the epidemiologic point of view, the increasing incidence of early stages of the disease is alarming. Men prevail over women among the infected persons; the men having sex with men (MSM) has been increasing in the last three years.

Key words: syphilis, Prague, epidemiology, symptoms, risks

Address for correspondence: I. Kuklová, Department of Dermatovenereology, General Teaching Hospital, U Nemocnice 2, 12800 Prague 2, Czech Republic. E-mail: ikuklova@post.cz

\section{INTRODUCTION}

Sexually transmitted diseases (STDs) other than HIV are important global health issues. They have, however, been neglected as a public health priority and control efforts continue to fail (1). Syphilis, like many other STDs, facilitates the spread of HIV by increasing the likelihood of transmission of the virus. Syphilis may increase HIV replication and immune demage. Conversely, HIV may speed treponemal dissemination and disease severity $(2,3)$.

Syphilis, a genital ulcerative disease, is highly infectious, but easily curable in its early (primary and secondary) stages. If untreated, it can lead to serious longterm complications, including brain, cardiovascular, and organ damage, and even death. Syphilis is classified as acquired or congenital. Congenital syphilis can cause stillbirth, death soon after birth, and physical deformity and neurological complications in children who survive. Acquired syphilis is divided into early- and late-syphilis. Early (infectious) syphilis: primary, secondary and early latent infection. The European Centre for Disease Prevention and Control (ECDC) defines early syphilis as syphilis acquired $<1$ year previously and the World Health Organization (WHO) defines early syphilis as syphilis acquired $<2$ years previously (4, 5). Late syphilis: late latent and tertiary syphilis (gummatous, cardiovascular and neurosyphilis).

\section{Clinical Manifestations}

Clinical manifestations separate the disease into stages. Infection is initiated when T. pallidum penetrates dermal microabrasions or intact mucous membranes, typically resulting in a single chancre at the site of inoculation. Moderate regional lymphadenopathy is associated with the primary stage. The chancre usually becomes indurated and will progress to ulceration but typically is not purulent. Within hours of inoculation, and during the evolution of the primary stage, T. pallidum disseminates widely and organisms are deposited in a variety of tissues (2).

Sore throat, muscle aches, malaise, and weight loss are examples of variable systemic symptoms of secondary syphilis. Generalized nontender lymphadenopathy occurs in up to $85 \%$ of cases. The most common manifestation of secondary syphilis is a disseminated mucocutaneous rash. Pale and discrete macular lesions appear initially on the trunk and proximal extremities; these are followed by lesions of various morphologies among patients. At diagnosis, the most common types of secondary syphilis lesions are maculopapular (in $50 \%$ to $70 \%$ of patients), papular $(12 \%)$, macular $(10 \%)$, and annular papular (6\% to $14 \%)$ $(6,7,8)$. Rash is frequently found on the palms of the hands and soles of the feet and, in $4 \%$ to $11 \%$ of patients, T. pallidum infection of hair follicles results in alopecia of the scalp. There have also been infrequent reports of facial and body hair loss. Concurrent with the appearance of secondary lesions, about $10 \%$ 
of patients develop condylomata lata. These enlarged lesions, appearing in warm and moist areas including the perineum and anus, are highly infectious. Localized inflammation of the oral cavity, tongue, and genital mucous membranes can cause mucous patches $(9,10)$; infrequently, secondary syphilis can be accompanied by gastric and renal involvement and hepatitis (11). Approximately $5 \%$ of individuals with secondary syphilis experience the early manifestations of neurosyphilis, including meningitis and ocular disease (6). Latency is the period between healing of the clinical lesions and appearance of late manifestations, and it can last for many years. About $70 \%$ of untreated individuals will remain in this stage for the rest of their lives. Latency is characterized by positive serologic tests for specific antibodies without clinical signs or symptoms. Infectivity may occur intermittently due to the presence of treponemes in the bloodstream, and pregnant women with latent syphilis may infect the fetus in utero. The tertiary stage is also called late syphilis and is characterized by the presence of a small number of organisms and a high cellular immune reactivity against the organism. Signs of late syphilis can be recognized in approximately one-third of untreated individuals several months to years after being infected with treponemes. The microorganisms can invade the central nervous or cardiovascular systems and the skin (as well as other organs) and lead to damage due to host delayed-type hypersensitivity responses, which produce local inflammation and gummas in affected tissues.

\section{Vaccine Development}

Up until now, there is no usable vaccine available. There are several reasons why active syphilis vaccine development efforts should continue. These include prevention of HIV transmission, prevention of congenital syphilis in developing nations and, last but not least, prevention of the possible serious late sequelae of untreated syphilis.

In many studies, immunization with T. pallidum molecules (e.g. endoflagella, Gpd, TmpB, Tp92, TpN15, TpN47, TprF) was conducted and protection against infectious challenge was determined. Immunization stimulated the production of strongly reactive antibodies, some of which were shown to be opsonic. These immunization regimens, however, induced only partial protection, shown by attenuated development and rapid healing of lesions. This lack of complete protection in the face of high antibody titers suggests that the cellular immune response is critical to early clearance of T. pallidum. The requirement for cellular immunity in syphilis protection is supported by the fact that passive transfer of antibodies against T. pallidum, or against one of its lipid components, does not completely protect against infection. Additionally, the recombinant molecules used for immunization in many of these studies are likely not to be folded in native conformation; thus, antibodies that bind to conformational epitopes of native antigen may not be produced by immunization. Finally, the first targets of the immune response, outer membrane proteins, are very rare in T. pallidum. The identification of molecules found on T. pallidum's surface is likely to be essential for the development of an effective syphilis vaccine. It is hoped that their discovery and use in a multivalent vaccine will lead to the production of an effective vaccine for syphilis (2).

\section{Epidemiology}

Syphilis is distributed worldwide and is particularly problematic in developing countries, where it is a leading cause of genital ulcer disease. The World Health Organization estimates that 12 million new cases of syphilis occur each year (12). Numbers and rates of infectious syphilis fell to their lowest levels in many European Union (EU) countries by the early 1990s (13, 14), despite substantial increases in syphilis incidence in Russia $(15,16)$. The decreases in western Europe were accompanied by marked reductions in the incidence of congenital syphilis and tertiary disease. By 1995, with the exception of Germany, fewer than 300 cases of infectious syphilis were recorded in any of the reporting EU countries. Since 1996, syphilis has again been on the increase in many northern and western EU countries (17), in part driven by increases in cases among men who have sex with men, although more recent increases among heterosexual people have also been reported. An increase in new cases has also been noted in eastern Europe since the dissolution of the Soviet Union. The number of reported cases increased dramatically in the Russian Federation, from 7,911 in 1990 to 392,616 in 1997, with a similar phenomenon observed in other Eastern European countries (18).

In the Czech Republic most cases of syphilis, total of 18,000 were diagnosed after the World War II during the mass screening of the population aged 15 to 40 years in 1951 (the "PN - venereal diseases action"). In the following years, the incidence of syphilis decreased considerably, the yearly incidence being in the range of hundreds. The incidence of syphilis has increased rapidly and substantially during the 1990s as a result of geopolitical and socioeconomic changes. The syphilis rate has risen eightfold, from 1.6 per 100,000 inhabitants in 1990 to 13.5 per 100,000 inhabitants in 2001 due to high proportion of syphilis cases among immigrants (Fig. 1). The proportion of immigrants rose from 5.4\% in 1990 to $59 \%$ in 2001 . Foreign patients came mainly from the Ukraine (42\%), Moldavia (12.5\%), the Russian Federation (8\%), and Georgia (8\%). From the epidemiologic point of view, the growth of the proportion of early syphilis (diagnosed within 2 years of infection) was significant in the 1990s. In 1990, the early form represented $24.4 \%$ of the total number of notified cases; in 1998 it had climbed to $65.6 \%$. Since 2000 , there has been an increase in the number of cases designated as late latent or of unknown duration, which represent $68.6 \%$ of the total number of reported cases in

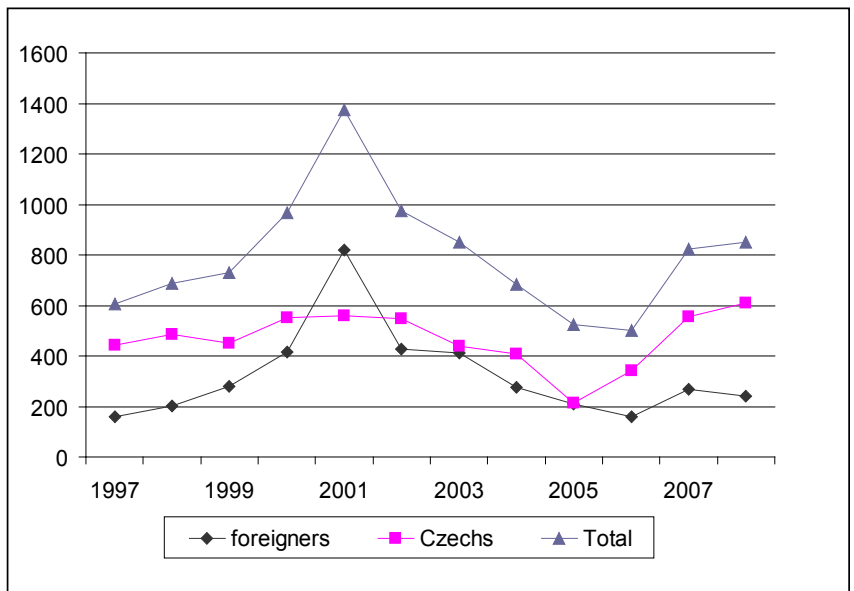

Fig 1. Number of syphilis cases in the Czech Republic. 
2005. Groups at increased risk for syphilis remain cohorts of men aged 25 to 29 years, and 30 to 34 years, with a peak at 30 years of age. The age distribution of women patients is wider, beginning in the 15 - to 19 -year age group and peaking at 25 years of age. The increase of infectious syphilis was also reflected in the occurrence of congenital syphilis. In 1998, 66 cases of syphilis in pregnant women and 18 cases of congenital syphilis were reported, the highest numbers since $1960(19,20,21)$. After reaching a peak in 2001 , the incidence of syphilis has been decreasing. After 2006, the incidence has increased again and the majority of these cases are in males. Migration of foreigners from Eastern Europe is likely to continue influencing the syphilis rates in the Czech Republic (20).

\section{METHODS}

A surveillance of new onset syphilis cases was conducted from the 1st January 2009 to the 31st December 2009 at the Department of Dermatovenereology of the General Teaching Hospital in Prague, which is the reference center for approximately 50\% of the Prague population. Syphilis cases were diagnosed based on clinical features, the serologic picture, and dark-field microscopy and based on analysis of the hospitalization records

\section{RESULTS}

Of the total number of 232 patients hospitalized with syphilis in 2009 (including 26 women admitted for compulsory retreatment in pregnancy), 206 were patients with newly diagnosed infection, of which $153(74.3 \%)$ were men and $53(25.7 \%)$ women. The data are shown in Tables 1-3. The male-female ratio was $3: 1$. As in 2008 , the majority of men were aged 30 to $40(34.6 \%)$ and over $40(29.4 \%)$. Most of women belonged to the age group of 25-29 and $30-40(43.4 \%)$. There were 41 (19.9\%) foreigners among the hospitalized patients, of which $26(63.4 \%)$ were men and 15 $(36.6 \%)$ women. As for the marital status, most of the patients were single, amounting to a total of $150(72.8 \%)$ persons, out of whom 117 were men (76.5\%) and 33 women (62.3\%). Approximately the same number of men and women were divorced $(11.1 \%$ and $11.3 \%$ ). Most women had only basic education (69.8\%). From the total number of patients, $47(22.8 \%)$ were unemployed.

Among men, there were $99(64.7 \%)$ men having sex with men (MSM). The majority of men had more than one sexual partner at the time of supposed syphilis infection (57.3\%). Equal number of men and women evaluated their sexual behaviour as promiscuous (16.5\%). Prostitution was reported by 4 men (2.6\%) and 13 (24.5\%) women. Compared to the previous surveys, significantly more men $(7.8 \%)$ and especially women $(20.8 \%)$ were injecting drug users. There were $116(56.3 \%)$ cigarette smokers. A total of 46 patients $(22.3 \%)$ were identified by contact tracing, $9.7 \%$ of patients were sent by their dermatologist; all of them were men. A total of $38.3 \%$ of patients came due to clinical symptoms without recommendation from any health facility. Only $2.9 \%$ of patients were admitted based on the result of a preoperative examination, $15.0 \%$ patients came on the basis of a preventive check-up. Four patients (1.9\%) were admitted with a serological relapse diagnosed within the follow-up treatment; all of them

Table 1. Demographic data

\begin{tabular}{|c|c|c|c|c|c|c|c|}
\hline \multirow{2}{*}{\multicolumn{2}{|c|}{ Sex }} & \multicolumn{2}{|c|}{ Men } & \multicolumn{2}{|c|}{ Women } & \multicolumn{2}{|c|}{ Total } \\
\hline & & \multirow{2}{*}{$\begin{array}{l}\text { No. } \\
153\end{array}$} & \multirow{2}{*}{$\begin{array}{c}\% \\
74.3\end{array}$} & \multirow{2}{*}{$\begin{array}{c}\text { No. } \\
53\end{array}$} & \multirow{2}{*}{$\begin{array}{c}\% \\
25.7\end{array}$} & \multirow{2}{*}{$\begin{array}{l}\text { No. } \\
206\end{array}$} & \multirow{2}{*}{$\begin{array}{c}\% \\
100.0\end{array}$} \\
\hline & & & & & & & \\
\hline \multirow{2}{*}{ Nationality } & Czech & 127 & 83.0 & 38 & 71.7 & 165 & 80.1 \\
\hline & Foreigners & 26 & 17.0 & 15 & 28.3 & 41 & 19.9 \\
\hline \multirow{2}{*}{ Country of birth } & Slovak & 11 & 42.3 & 3 & 20.0 & 14 & 34.1 \\
\hline & Ukraine & 3 & 11.5 & 9 & 47.4 & 12 & 29.3 \\
\hline \multirow{2}{*}{ Permanent address } & Prague & 88 & 57.5 & 23 & 43.4 & 111 & 53.9 \\
\hline & Other & 65 & 42.5 & 30 & 56.6 & 95 & 46.1 \\
\hline \multirow{5}{*}{ Age } & $15-19$ & 0 & 0.0 & 3 & 5.7 & 3 & 2.0 \\
\hline & $20-24$ & 18 & 11.8 & 8 & 15.1 & 26 & 12.6 \\
\hline & $25-29$ & 37 & 24.2 & 12 & 22.6 & 49 & 23.8 \\
\hline & $30-40$ & 53 & 34.6 & 23 & 43.4 & 76 & 36.9 \\
\hline & $>41$ & 45 & 29.4 & 7 & 13.2 & 52 & 25.2 \\
\hline \multirow{4}{*}{ Marital status } & Married & 18 & 11.8 & 14 & 26.4 & 32 & 15.5 \\
\hline & Single & 117 & 76.5 & 33 & 62.3 & 150 & 72.8 \\
\hline & Divorced & 17 & 11.1 & 6 & 11.3 & 23 & 11.2 \\
\hline & Widow & 1 & 0.6 & 0 & 0.0 & 1 & 0.5 \\
\hline \multirow{3}{*}{ Education } & $<$ High school & 65 & 42.5 & 37 & 69.8 & 102 & 49.5 \\
\hline & High school & 49 & 32.0 & 14 & 26.4 & 63 & 30.6 \\
\hline & University & 39 & 25.5 & 2 & 3.8 & 41 & 19.9 \\
\hline
\end{tabular}


Table 2. Behaviour characteristics

\begin{tabular}{|c|c|c|c|c|c|c|c|}
\hline & & \multicolumn{2}{|c|}{ Men } & \multicolumn{2}{|c|}{ Women } & \multicolumn{2}{|c|}{ Total } \\
\hline & & No. & $\%$ & No. & $\%$ & No. & $\%$ \\
\hline \multirow{2}{*}{ Sexual orientation } & MSM & 99 & 64.7 & 0 & 0.0 & 99 & 48.5 \\
\hline & Heterosexual & 54 & 35.3 & 53 & 100.0 & 106 & 51.5 \\
\hline \multicolumn{2}{|l|}{ Prostitution } & 4 & 2.6 & 13 & 24.5 & 17 & 8.3 \\
\hline \multirow{4}{*}{$\begin{array}{l}\text { Number of sex } \\
\text { partners. past } \\
12 \text { months }\end{array}$} & 1 & 30 & 19.6 & 25 & 47.1 & 55 & 26.7 \\
\hline & $2-3$ & 74 & 48.4 & 10 & 18.9 & 84 & 40.8 \\
\hline & Promiscuous & 25 & 16.3 & 9 & 17.0 & 34 & 16.5 \\
\hline & No records & 24 & 15.7 & 9 & 17.0 & 33 & 16.0 \\
\hline \multirow{3}{*}{ Cigarette smokers } & Yes & 89 & 58.2 & 27 & 50.9 & 116 & 56.3 \\
\hline & No & 59 & 38.6 & 25 & 47.2 & 84 & 40.8 \\
\hline & ex-smoker & 5 & 3.2 & 1 & 1.9 & 6 & 2.9 \\
\hline \multicolumn{2}{|l|}{ Injecting drug users } & 12 & 7.8 & 11 & 20.8 & 23 & 11.2 \\
\hline
\end{tabular}

were men, $9.2 \%$ patients were admitted with re-infection. Of the $171(83.0 \%)$ patients with early syphilis (diagnosed within 2 years of infection), 141 (92.2\%) were men and 30 (56.6\%) were women. Symptomatic syphilis was diagnosed in 111 cases (alone or in combinations), a total of $46(22.3 \%)$ patients (43 men and three women) had a genital chancre. Extra-genital chancre was found in four cases, two men (lips) and two women (upper lip and tongue). Dark-field microscopy was positive in 20 (9.7\%) cases. Most of the patients were treated with penicillin antibiotics; seven patients received doxycycline because of known allergy to penicillin. Jarisch-Herxheimer $(\mathrm{JH})$ reaction (pronounced febrile reaction accompanied by an aggravation of the syphilitic symptoms) occurred in $83(40.3 \%)$ patients, 72 men and 11 women. $\mathrm{JH}$ reaction was observed in nearly three quarters of patients with symptomatic syphilis. Of the total number of men, $5.9 \%$ had had gonorrhoea in the past. Gonorrhoea/syphilis co-infection was diagnosed in 9 men and 3 women. Hepatitis C, which is not routinely tested in syphilis patients, was newly diagnosed in 2 men and 1 woman. Mycoplasma infections were identified in 1 man and 5 women. Four men were HIV positive; three of them were MSM; all were single; one of them was newly diagnosed and admitted promiscuous behaviour.

\section{DISCUSSION}

All clinicians and laboratories in the Czech Republic have a statutory obligation to complete case reports of syphilis, gonorrhoea, ulcus molle, lymphogranuloma venereum, or granuloma inguinale and send them to the Department of Epidemiology of

Table 3. Clinical data

\begin{tabular}{|c|c|c|c|c|c|c|c|}
\hline & & \multicolumn{2}{|c|}{ Men } & \multicolumn{2}{|c|}{ Women } & \multicolumn{2}{|c|}{ Total } \\
\hline & & No. & $\%$ & No. & $\%$ & No. & $\%$ \\
\hline \multirow{9}{*}{ Referred by } & Contact tracing & 29 & 19.0 & 17 & 32.1 & 46 & 22.3 \\
\hline & General practitioner & 5 & 3.3 & 1 & 1.9 & 6 & 2.9 \\
\hline & Dermatologist & 20 & 13.1 & 0 & 0.0 & 20 & 9.7 \\
\hline & Gynaecologist & 0 & 0.0 & 3 & 5.7 & 3 & 1.5 \\
\hline & Self-referred. asymptomatic & 4 & 2.6 & 1 & 1.9 & 5 & 2.4 \\
\hline & Self-referred. symptomatic & 75 & 49.0 & 4 & 7.5 & 79 & 38.3 \\
\hline & Preventive screening & 18 & 11.8 & 13 & 24.5 & 31 & 15.1 \\
\hline & Preoperative examination & 2 & 1.3 & 4 & 7.5 & 6 & 2.9 \\
\hline & Antenatal clinic & 0 & 0.0 & 10 & 18.9 & 10 & 4.9 \\
\hline \multirow{7}{*}{ Symptoms * } & Discharge & 10 & 5.3 & 1 & 1.6 & 11 & 4.4 \\
\hline & Ulcers & 52 & 27.5 & 5 & 8.1 & 57 & 22.7 \\
\hline & Exanthema & 37 & 19.6 & 3 & 4.8 & 40 & 15.9 \\
\hline & Fear from STD & 31 & 16.4 & 10 & 16.1 & 41 & 16.3 \\
\hline & Partner's infection & 29 & 15.3 & 17 & 27.4 & 46 & 18.3 \\
\hline & Prevention & 11 & 5.8 & 12 & 19.4 & 13 & 5.2 \\
\hline & Treatment & 19 & 10.1 & 14 & 22.6 & 33 & 13.2 \\
\hline
\end{tabular}




\begin{tabular}{|c|c|c|c|c|c|c|c|}
\hline \multirow[t]{3}{*}{ Dark-field microscopy } & Missing & 115 & 75.2 & 48 & 90.1 & 163 & 79.1 \\
\hline & Positive & 16 & 10.4 & 4 & 7.5 & 20 & 9.7 \\
\hline & Negative & 22 & 14.4 & 1 & 1.9 & 23 & 11.2 \\
\hline \multirow[t]{3}{*}{ Character of infection } & First time & 131 & 85.6 & 52 & 98.1 & 183 & 88.9 \\
\hline & Serological relapse & 4 & 2.6 & 0 & 0.0 & 4 & 1.9 \\
\hline & Re-infection & 18 & 11.8 & 1 & 1.9 & 19 & 9.2 \\
\hline \multirow[t]{9}{*}{ Symptomatic syphilis * } & Missing & 57 & 37.3 & 38 & 71.7 & 95 & 46.1 \\
\hline & Present & 96 & 62.7 & 15 & 28.3 & 111 & 53.9 \\
\hline & Chancre & 47 & 30.7 & 3 & 5.7 & 50 & 24.3 \\
\hline & Macular or papular rash & 50 & 32.7 & 7 & 13.2 & 57 & 27.7 \\
\hline & Condylomata lata & 5 & 3.3 & 5 & 9.4 & 10 & 4.8 \\
\hline & Lymphadenitis & 35 & 22.9 & 4 & 7.5 & 39 & 18.9 \\
\hline & Angina syphilitica & 5 & 3.3 & 3 & 5.7 & 8 & 3.9 \\
\hline & Palmoplantar syphilis & 11 & 7.2 & 1 & 1.9 & 12 & 5.8 \\
\hline & Alopecia & 1 & 0.6 & 0 & 0.0 & 1 & 0.5 \\
\hline \multirow[t]{4}{*}{ Stage of syphilis } & Primary & 43 & 28.1 & 3 & 5.7 & 46 & 22.3 \\
\hline & Early secondary & 55 & 35.9 & 10 & 18.9 & 65 & 31.6 \\
\hline & Early latent & 43 & 28.1 & 17 & 32.0 & 60 & 29.1 \\
\hline & Late latent & 12 & 7.8 & 23 & 43.4 & 35 & 17.0 \\
\hline \multirow[t]{4}{*}{ Treatment } & Procaine PNC G + Benzathine PNC** & 91 & 59.5 & 27 & 50.9 & 118 & 57.3 \\
\hline & Benzathine PNC & 55 & 35.9 & 25 & 47.2 & 80 & 38.8 \\
\hline & Aqueous cryst. PNC + Benzathine PNC*** & 1 & 0.7 & 0 & 0.0 & 1 & 0.5 \\
\hline & Doxycycline & 6 & 3.9 & 1 & 1.9 & 7 & 3.4 \\
\hline \multirow[t]{2}{*}{ Jarish-Herxheimer reaction } & Yes & 72 & 47.1 & 11 & 20.8 & 83 & 40.3 \\
\hline & No & 81 & 52.9 & 42 & 79.2 & 123 & 59.7 \\
\hline \multirow[t]{2}{*}{ HIV tested at our department } & Yes & 97 & 63.4 & 19 & 35.8 & 116 & 56.3 \\
\hline & No & 56 & 36.6 & 34 & 64.2 & 90 & 43.7 \\
\hline \multirow[t]{4}{*}{ co-infections } & Gonorrhoea & 9 & 5.9 & 3 & 5.7 & 12 & 5.8 \\
\hline & Chlamydial infection & 7 & 4.6 & 1 & 1.9 & 8 & 3.9 \\
\hline & Mycoplasma infections & 1 & 0.7 & 5 & 9.4 & 6 & 2.9 \\
\hline & HIV & 4 & 2.6 & 0 & 0.0 & 4 & 1.9 \\
\hline \multicolumn{2}{|l|}{ History of STD infection } & 37 & 24.2 & 10 & 18.9 & 47 & 22.8 \\
\hline
\end{tabular}

* multi-response answer

** Procaine penicillin G. plus Benzathine penicillin G

${ }^{* * *}$ Aqueous crystalline penicillin plus Benzathine penicillin

the Public Health Offices. Accredited epidemiologists cooperate with clinicians and laboratories in checking reported data, confirmation of diagnosis, treatment, and examination of contact persons. This information is then transferred to the National Registry of Venereal Diseases (NRVD). Statistically processed anonymous data are classified by individual diagnosis, age, sex, patient's residence, and other factors, and the outputs are made available regionally on a quarterly basis and annually for the entire country. Annual reports are edited by the Czech Ministry of Health's Institute of Health Information and Statistics. Relevant issues cover the data on syphilis, gonorrhoea, chancroid, and lymphogranuloma venereum going back to $1959(21,22)$. Czech legislation stipulates that syphilis patients must be treated in the hospital only. A retrospective case note review of patients diagnosed and hospitalized with acquired syphilis in 2009 at the Department of Dermatovenereology was performed.
Our data on Prague's population basically correspond with the nationwide records. The reason for the rising syphilis notification rate has been credited to the political and socioeconomic changes in the Czech Republic in 1989 that have resulted in increased travel, economic migration, income differentials, dramatic increases in commercial sex and more open sex industry. From the epidemiologic point of view, the increase of the number of early infectious forms is significant. Their proportion was highest in $1996(71.0 \%)$, declined to $35 \%$ in 2006 and rose again to $60.3 \%$ ( 4.9 cases per 100,000 inhabitants) in 2008. In our patients, the increased incidence of early forms is even more significant. Another trend is an increase in the number of infected men. While the proportion of hospitalized men and women was equal until 2006 , in the last three years, we have recorded an increase among males, the male-female ratio being 3:1 in 2009. Compared to the previous study from 1999-2005, we have seen a significant 
increase of syphilis incidence in MSM $(19,23)$. This trend corresponds to the situation in developed West European countries. In the developed European countries and USA, isolated outbreaks can be observed in homosexual communities, which are accounted for by the improved health condition of HIV-infected men, the highly active antiretroviral therapy and its better accessibility, the use of methamphetamine and Viagra and unprotected oral and anal intercourses $(17,24,25)$. These minor outbreaks were described for example in Dublin in 2001 through 2003, where $31 \%$ of homosexual men reported an unprotected oral intercourse and $15.9 \%$ unprotected anal intercourse (26). Similar findings have been reported from Manchester, Bristol and London (27, 28 ). In Denmark in 2004 , homosexual men accounted for $78 \%$ of all newly reported cases, $37 \%$ of them being HIV-positive (29). Similar data were reported from Belgium and Germany. In 2003, the syphilis incidence in Germany was 10 times higher among men than among women (75\% of them being homosexuals and $50 \% \mathrm{HIV}$-positive). According to foreign studies, HIV/syphilis co-infection in homosexual men ranges from 20 to $73 \%$ (27, $30,31)$. The data on HIV/syphilis co-infection rates are lower among our patients, which is in concordance with relatively low HIV prevalence in the Czech Republic. From the launch of the National HIV/AIDS Monitoring Program to December 31, 2009, as many as 1,344 HIV-positive patients were recorded in the Czech Republic, of whom 292 were diagnosed as having fully developed AIDS that resulted in 156 deaths. The Czech Republic notified 157 new HIV cases which was about 10 more then in 2008. Sexual contact remains the most frequent mode of HIV transmission in the Czech Republic, accounting for $91 \%$ of the total number of cases registered to date. MSM are at the highest risk of HIV transmission (64.3\% of newly diagnosed HIV cases in 2009). The current reporting system does not capture data on HIV and syphilis co-infection; including these data into the reporting system would be important for initiating targeted prevention measures (32). In heterosexual men, primary chancres most commonly occur on the penis, but 32 to $36 \%$ of homosexual men have primary chancres in other sites, including the rectum, anal canal, and oral cavity $(33,34)$. The extragenital lesions among our patients were rare, suggesting that they were overlooked by the patients.

\section{CONCLUSIONS}

In the last four years, we have seen an increase in the number of syphilis cases among patients treated at the Department of Dermatovenereology in Prague, in line with nationwide trends. The age distribution did not change; majority of the patients were aged between 30 and 40 . The proportion of foreigners also remained unchanged; they came mainly from the Slovak Republic and Ukraine. The increasing number of early symptomatic infections and infected homosexual men are the most significant epidemiologic findings, although heterosexual contact remained the most frequent route of syphilis transmission. This trend confirms the importance of contact-tracing, HIV and syphilis testing and the presumptive negative consequences of the abandonment of the serologic screening during the first hospitalization in the given year, which is no longer required by Czech legislation. Interventions delivered to whole populations, or groups in whom the risks of infection and onward transmission are very high, have the greatest potential effect. Effective action requires a multifaceted approach including better basic epidemiological and surveillance data supported by high quality evidence about effectiveness of individual interventions and programmes (1).

\section{Acknowledgements}

This work was supported by the Ministry of Health of the Czech Republic (Grant IGA MZ CR: NS-10292-3)

\section{REFERENCES}

1. Low N, Broutet N, Adu-Sarkodie Y, Barton P, Hossain M, Hawkes S. Global control of sexually transmitted infections. Lancet. 2006 Dec 2;368(9551):2001-16.

2. Lafond RE, Lukehart SA. Biological basis for syphilis. Clin Microbiol Rev. 2006 Jan;19(1):29-49.

3. Daskalakis D. Syphilis: continuing public health and diagnostic challenges. Curr HIV/AIDS Rep. 2008 May;5(2):72-7.

4. European Centre for Disease Prevention and Control (ECDC) [Internet]. Stockholm: ECDC; 2011 [updated 2011; cited 2011 March 9]. Available from: http://ecdc.europa.eu/.

5. World Health Organization. Sexually transmitted infections management guidelines [Internet]. Geneva: WHO; 2004 [cited 2009 March 2]. Available from: http://www.who.int/reproductive-health/stis/guidelines/ mngt_stisguidelines_mgnt-stis.pdf.

6. Baughn RE, Musher DM. Secondary syphilitic lesions. Clin Microbiol Rev. 2005 Jan;18(1):205-16.

7. Chapel TA. The signs and symptoms of secondary syphilis. Sex Transm Dis. 1980 Oct-Dec;7(4):161-4

8. Hira SK, Patel JS, Bhat SG, Chilikima K, Mooney N. Clinical manifestations of secondary syphilis. Int J Dermatol. 1987 Mar;26(2):103-7.

9. Kuklová I. Sexually transmitted infections. In: Weiss P, et al. Sexuology. Praha: Grada Publishing; 2010. p. 579 - 612. (In Czech.)

10. Štork J. Dermatovenereology in chapters. Prague: Galén; 2008. (In Czech.)

11. Greenstein DB, Wilcox CM, Schwartz DA. Gastric syphilis. Report of seven cases and review of the literature. J Clin Gastroenterol. 1994 Jan;18(1):4-9.

12. Gerbase AC, Rowley JT, Heymann DH, Berkley SF, Piot P. Global prevalence and incidence estimates of selected curable STDs. Sex Transm Infect. 1998 Jun;74 Suppl 1:S12-6.

13. Nicoll A, Hamers FF. Are trends in HIV, gonorrhoea, and syphilis worsening in western Europe? BMJ. 2002 Jun 1;324(7349):1324-7.

14. Fenton KA, Breban R, Vardavas R, Okano JT, Martin T, Aral S, et al Infectious syphilis in high-income settings in the 21 st century. Lancet Infect Dis. 2008 Apr;8(4):244-53.

15. Bingham JS, Waugh MA. Sexually transmitted infections in the Russian Federation, the Baltic States and Poland. Int J STD AIDS. 1999 Oct;10(10):657-8.

16. Hiltunen-Back E, Haikala O, Koskela P, Vaalasti A, Reunala T. Epidemics due to imported syphilis in Finland. Sex Transm Dis. 2002 Dec;29(12):746-51.

17. Fenton KA, Lowndes CM. Recent trends in the epidemiology of sexually transmitted infections in the European Union. Sex Transm Infect. 2004 Aug;80(4):255-63.

18. Borisenko KK, Tichonova LI, Renton AM. Syphilis and other sexually transmitted infections in the Russian Federation. Int J STD AIDS. 1999 Oct;10(10):665-8.

19. Kuklová I, Kojanová M, Zákoucká H, Pánková R, Velcevský P, Rozehnalová Z, et al. Dermatovenereology in the post-communist era: syphilis in Prague during 1999 to 2005. Dermatol Clin. 2008 Apr;26(2):231-7, vi.

20. Institute of Health Information and Statistics of the Czech Republic. Venereal diseases 2008. Praha: ÚZIS; 2009. (In Czech.)

21. Zákoucká H, Polanecký V, Kastánková V. Syphilis and gonorrhoea in the Czech Republic. Euro Surveill. 2004 Dec;9(12):18-20.

22. Resl V. The governmental surveillance in venereology. Čes-slov Derm. 2005;80(2):102-3. (In Czech.)

23. Kuklová I, Kojanová M, Velčevský P, et al. Analysis of causes of rising syphilis incidence in the Prague population. Čes-slov Derm. 2008;84:3506. (In Czech.) 
24. Giuliani M, Palamara G, Latini A, Maini A, Di Carlo A. Evidence of an outbreak of syphilis among men who have sex with men in Rome. Arch Dermatol. 2005 Jan;141(1):100-1.

25. Lynn WA, Lightman S. Syphilis and HIV: a dangerous combination. Lancet Infect Dis. 2004 Jul;4(7):456-66.

26. Cronin M, Domegan L, Thornton L, Fitzgerald M, Hopkins S, O’Lorcain $\mathrm{P}$, et al. The epidemiology of infectious syphilis in the Republic of Ireland. Euro Surveill. 2004 Dec;9(12):14-7.

27. Lacey HB, Higgins SP, Graham D. An outbreak of early syphilis: cases from North Manchester General Hospital. Sex Transm Infect. 2001 Oct;77(5):311-3.

28. Poulton M, Dean GL, Williams DI, Carter P, Iversen A, Fisher M. Surfing with spirochaetes: an ongoing syphilis outbreak in Brighton. Sex Transm Infect. 2001 Oct;77(5):319-21.

29. Cowan S. Syphilis in Denmark-Outbreak among MSM in Copenhagen, 2003-2004. Euro Surveill. 2004 Dec;9(12):25-7.
30. Hopkins S, Lyons F, Coleman C, Courtney G, Bergin C, Mulcahy F. Resurgence in infectious syphilis in Ireland: an epidemiological study. Sex Transm Dis. 2004 May;31(5):317-21.

31. Marcus U, Hamouda O, Kiehl W. Reported incidence of gonorrhoea and syphilis in East and West Germany 1990-2000 - effects of reunification and behaviour change. Euro Surveill. 2001;5(43):pii=2042.

32. Rozehnalová Z, Hercogová J, Jilich D, Machala L, Rozsypal H. Syphilis and HIV co-infection. Čes-slov Derm. 2008;84:278-85. (In Czech.)

33. Hourihan M, Wheeler H, Houghton R, Goh BT. Lessons from the syphilis outbreak in homosexual men in east London. Sex Transm Infect. 2004 Dec;80(6):509-11.

34. Mindel A, Tovey SJ, Timmins DJ, Williams P. Primary and secondary syphilis, 20 years' experience. 2. Clinical features. Genitourin Med. 1989 Jan;65(1):1-3.

Received August 12, 2010 Accepted in revised form January 27, 2011 